\title{
ANALISIS MOTIVASI BELAJAR PADA KETERAMPILAN MENYIMAK SISWA KELAS III SDS MUHAMMADIYAH 06 TEBET
}

\author{
Jihan Fadhilah", Rudi Ritonga ${ }^{2}$ \\ ${ }^{1}$ Universitas Trilogi \\ Email: fadhilahiihan265@gmail.com \\ ${ }^{2}$ Universitas Trilogi \\ Email: rudi ritonga@trilogi.ac.id
}

\begin{abstract}
Abstrak
Latar belakang penelitian ini adalah peneliti ingin mengetahui dan mendeskripsikan lebih lanjur tentang analisis motivasi belajar pada keterampilan menyimak siswa kelas III SDS Muhammadiyah 06 Tebet. Penelitian ini bertujuan untuk menganalisis motivasi belajar pada keterampilan menyimak siswa kelas III SDS Muhammadiyah 06 Tebet, untuk memjelaskan bagaimana proses pembelajaran dalam analisis motivasi belajar pada keterampilan menyimak siswa kelas III SDS Muhammadiyah 06 Tebet serta faktor apakah yang dapatmeningkatkan motivasi belajar dan upaya guru dalam menjaga kualitas motivasi belajar pada keterampilan menyimak siswa. Hasil penelitian menjukkan bahwa proses pembelajaran dalam analisis motivasi belajar pada keterampilan menyimak siswa, dilakukan dengan menggunakan aplikasi google meet, whatsapp group dan website kejar cita. Faktor yang dapat meningkatkan motivasi belajar pada keterampilan menyimak siswa, terdapat 2 motivasi ialah motivasi intrinsik dan motivasi ekstrinsik yang kedua nya sangat berpengaruh dalam sebuah proses pembelajaran. Motivasi intrinsik terdapat dalam diri siswa karena adanya semangat dan cita-cita yang ingin dicapai serta motivasi ekstrinsik diberikan oleh guru, orang tua, teman dan lingkungan maka dapat meningkatkan hasil belajar siswa. upaya guru dalam menjaga kualitas motivasi belajar terhadap keterampilan menyimak siswa dengan memberikan video, kata-kata motivasi sebelum memulai pebelajaran, dan memberikan pembelajaran yang aktif dan menyenangkan.
\end{abstract}

Kata kunci: Motivasi belajar, keterampilan menyimak, pembelajaran daring

\begin{abstract}
The background of this reseacrh is that the researchis wants to know and describe further about the analysis of learning motivation on the listening skills of third grade students of SDS Muhammadiyah 06 Tebet. This study aims to analyze the learning motivation of the grade students of SDS Muhammadiyah 06 Tebet, explain how the learning process in analiyzing the learning motivation of the third grade students of SDS Muhammadiyah 06 Tebet is listening and what factors can incrase learning motivation and teacher efforts to maintain qualitu. Learning motivation on students: listening skills. The results of the study show that the learning process in the analysis of learning motivation on students'listening process in the analysis of learning motivation on stundents' listening skills is carried out using the Google Meet aplication, WhatsApp group and the Kejar Cita website. Factors that can increse learning motivation in students' listening skills, there are 2 motivations, namely instrinsic motivation and extrinsic motivation, both of which are veri influential in a learning process. Intrinsic motivation is found in students because of the spririt and ideals to be achieved and extrinsic motivation given by teachers, parents, friends and the environment can improve student learning outcomes. The teacher's efforts in maintaining the quality of learning motivation on students' listening skills by providing video, motivatonal words before strating learning, and providing active and fun learning
\end{abstract}

Keywords: Motivation Learning, Listening Skill, Online Learning 


\section{Pendahuluan}

Pendidikan pada dasarnya adalah proses peningkatan kualitas hidup yang melalui proses ini diharapkan manusia dapat memahami makna dan hakikat kehidupan, serta bagaimana menjalankan tanggung jawab hidup dan hidup dengan benar (Bahar Yuliana, 2021). Berdasarkan UU No. 20 Tahun 2003 menegaskan bahwa pendidikan adalah suatu usaha sadar serta terencana untuk dapat mewujudkan suasana belajar dan proses pembelajaran supaya peserta didik dengan secara aktif mengembangkan atau menggali potensi dirinya untuk bisa atau dapat mempunyai kekuatan pengendalian diri, spritual keagamaan, kecerdasan, akhlak mulia, kepribadian dan juga keterampilan yang diperlukan bagi dirinya, bagi masyarakat, bagi bangsa, dan bagi negara yang bertujuan tujuan pendidikan nasional adalah untuk mengembangkan potensi peserta didik agar menjadi manusia yang beriman dan bertakwa kepada Tuhan Yang Maha Esa, sehat, berilmu, cakap, kreatif, mandiri, dan menjadi warga negara yang demokratis serta bertanggung jawab. Kondisi pendidikan saat ini mengharuskan guru lebih kreatif, aktif dan inovatif dalam proses pembelajaran dikarenakan lamanya siswa belajar di rumah. Pembelajaran daring ini menjadi tantangan bagi dunia pendidikan dengan situasi yang saat ini terjadi. Dampak dari pembelajaran daring ini adalah kurangnya motivasi belajar siswa dikarenakan siswa cukup lama tidak belajar secara tatap muka. Dengan proses pembelajaran siswa hanya melihat guru dari laptop ataupun handphone yang setiap harinya dilalui oleh siswa, yang menyebabkan siswa mengalami kejenuhan. Maka dari itu kemampuan menyimak siswa juga menurun, dikarenakan ada siswa yang sering mengantuk ataupun asyik dengan sendirinya ketika guru sedang menyampaikan materi. Berdasarkan hasil

79 | Analisis Motivasi Belajar pada Keterampilan Menyimak 
studi pendahuluan yang peneliti lakukan pada guru kelas III SDS Muhammadiyah 06 Tebet. Pada bulan Agustus 2021 melalui metode wawancara terkait analisis motivasi belajar pada keterampilan menyimakp. Guru menggunakan media pembelajaran seperti video, ppt dan gambar. Guru menggunakan aplikasi google meet, whatsapp group, website kejar cita dan menggunakan metode ceramah, diskusi, dan tanya jawab. dan ditunjang hasil dokumentasi ketika pembelajaran. Berdasarkan kegiatan pembelajaran tersebut maka dari hasil observasi, analisis motivasi belajar siswa pada keterampilan menyimak siswa kelas III SDS Muhammadiyah 06 Tebet minat motivasi siswa sudah baik, namun jika siswa tidak diberikan motivasi maka tingkat menyimak siswa rendah dan sebaliknya jika siswa diberikan motivasi maka tingkat menyimak siswa semakin tinggi.
Motivasi adalah perubahan energi dalam kepribadian yang ditandai dengan munculnya emosi (perasaan) dan respon untuk mencapai tujuan tertentu (Djamarah, 2017). Fungsi motivasi adalah sebagai mewujudkan ke tujuan yang ingin dicapai. Motivasi intrinsik adalah salah satu tujuan pembelajaran, hal tersebut dapat dibuktikan dengan keberhasilan siswa dalam belajar, diantaranya melalui tes dan evaluasi. Siswa membutuhkan motivasi karena banyak gejala yang muncul ketika terjadi kesalahan dan mempengaruhi hasil belajar dan keberhasilan siswa (Harianti dan Amin, 2016). Motivasi ekstrinsik yang aktif dan fungsional karena adanya rangsangan dari luar (Sardiman, 2018). Menyimak adalah aktivitas paling dasar yang harus dikuasai siswa sebelum terlibat dalam empat aktivitas bahasa lainnya. Beberapa alasan pembelajaran menyimak belum terlaksana dengan baik, yaitu karena pemahaman isi dan metode menyimak masih terbatas, sarana dan prasarana 
ISSN 2548-9119

kegiatan menyimak terbatas, media yang digunakan untuk pembelajaran menyimak belum menarik minat seseorang Perhatian pendengar dan metode yang digunakan tidak sejalan dengan perkembangan pendengar (Kusuma, 2017).

Rumusan masalah dari penelitian ini adalah Bagaimana proses pembelajaran dalam analisis motivasi belajar pada keterampilan menyimak siswa kelas III di SDS Muhammadiyah 06 Tebet, faktor apakah yang dapat meningkatkan motivasi belajar pada keterampilan menyimak siswa kelas III di SDS Muhhammadiyah 06 Tebet, bagaimana upaya guru dalam menjaga kualitas motivasi belajar siswa terhadap pembelajaran keterampilan menyimak siswa kelas III SDS Muhammadiyah 06 Tebet. Tujuan dari penelitian ini agar peneliti dan pembaca mengetahui motivasi belajar pada keterampilan menyimak siswa.

\section{Metode Penelitian}

Penelitian ini merupakan penelitian analisis deskriptif kualitatif. Metode penelitian kualitatif untuk menghasilkan data deskriptif, bertujuan untuk mengeksplorasi dan mengapresiasi objek, penelitian kualitatif bertujuan untuk memahami fenomena yang dialami oleh objek penelitian, seperti perilaku, persepsi, perilaku dll (kholifaj \& Suyadnya, 2018).

Lokasi penelitian adalah tempat yang dipilih oleh peneliti untuk melaksanakan penelitian untuk memperoleh data yang berkaitan dengan permasalahan penelitian. tempat yang akan dijadikan lokasi yaitu SDS Muhammadiyah 06 Tebet berada di J. Tebet Timur Raya No.565, RT.10/RW.5, Kelurahan Tebet Timur, Kecamatan Tebet, Kota Jakarta Selantan, Provinsi DKI Jakarta 12820, No.Telepon (021)835127. Subjek penelitian deskriptis kualitatif ini adalah siswa kelas III SDS 
Muhammadiyah dengan jumlah siswa pembelajaran keterampilan menyimak. dalam satu kelas 27 orang.

Hasil penelitian ini sebagai berikut:

Hasil dan Pembahasan

1. Proses pembelajaran dalam analisis

Penelitian ini membahas tentang motivasi belajar pada keterampilan analisis motivasi belajar pada menyimak

keterampilan menyimak siswa kelas III

Berdasarkan hasil observasi yang SDS Muhammadiyah 06 Tebet. dilakukan oleh peneliti terhadap siswa Penelitian ini menghasilkan proses kelas III tersebut adalah sebagai berikut pembelajaran dalam analisis motivasi Proses pembelajaran dalan analisis belajar pada keterampilan menyimak, motivasi belajar pada keterampilan Faktor yang dapat meningkatkan motivasi menyimak siswa kelas III di SDS belajar pada keterampilan menyimak Muhammadiyah menggunkan aplikasi siswa, Upaya guru dalam menjaga google meet, whatsapp group dan kualitas motivasi belajar siswa terhadap website kejar cita.

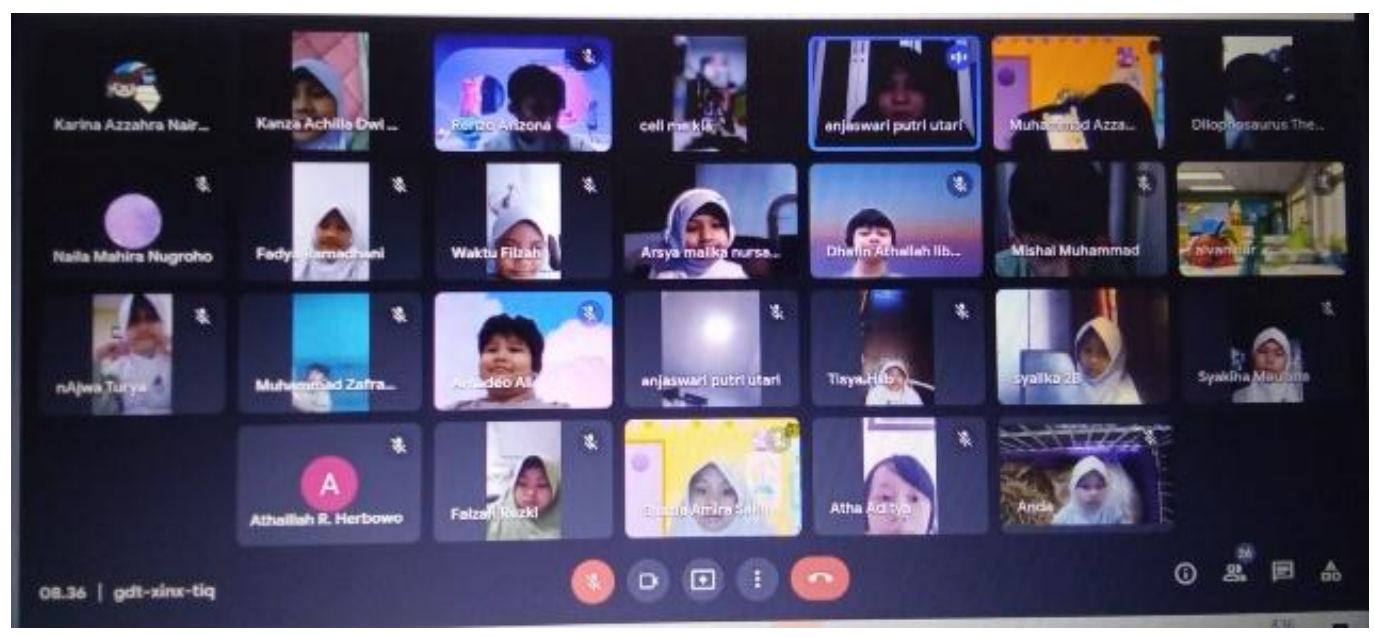

82 | Autentik: Jurnal Pengembangan Pendidikan Dasar, Vol. 6, No. 1, Februari 2022 
ISSN 2548-9119

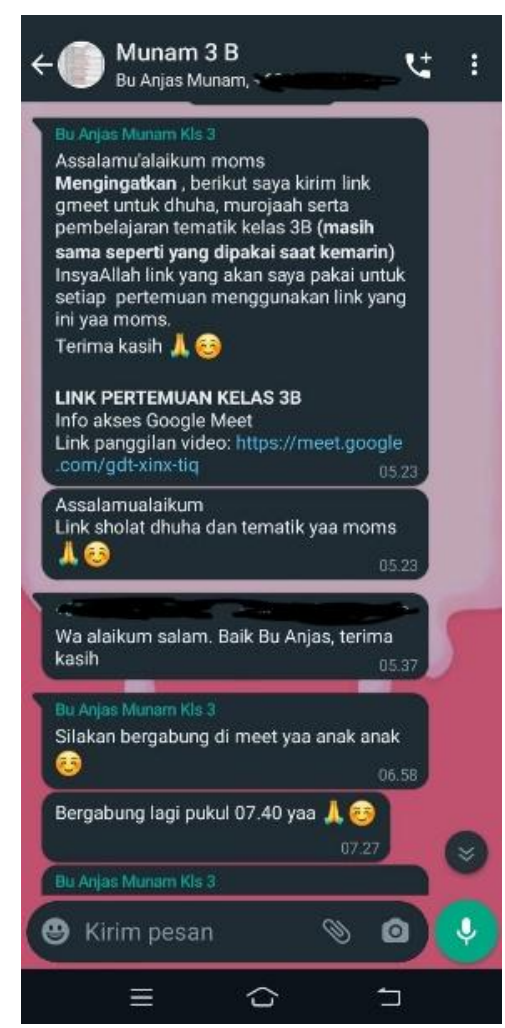

\section{Gambar 1: Proses Pemeblajaran Daring}

Dengan menggunakan media Motivasi dalam pembelajaran seperti power point, video dan gambar sangat penting di berikan oleh guru yang di sharescreen melalui aplikasi kepada siswa. Karena dengan adanya google meet maka diharapkan agar siswa motivasi siswa dapat mencapai suatu tetap dapat menerima informasi yang tujuan yang diharapkan. Jenis motivasi diberikan oleh guru dengan baik. Hanya dibedakan menjadi dua yaitu motivasi saja guru belum memberikan inovasi ekstrinsik dan motivasi intrinsik, yang baru dalam pembelajaran, guru keduanya sangat berpengaruh dalam masih menggunakan metode ceramah, sebuah proses pembelajaran. Adapun hal metode diskusi dan tanya jawab. yang harus di perhatikan adalah indikator

2. Faktor yang dapat meningkatkan motivasi belajar dan indikator motivasi belajar pada keterampilan keterampilan menyimak, agar tujuan menyimak pembelajaran belajar mendapatkan hasil

83 | Analisis Motivasi Belajar pada Keterampilan Menyimak. 
yang baik dan memuaskan. Dengan temannya yang mendapat nilai yang adanya motivasi yang diberikan oleh guru bagus, maka berlomba-lomba ingin maka dapat meningkatkan semangat mendapatkan nilai yang bagus juga. Dan belajar siswa dan sebaliknya jika belum untuk motivasi ekstrinsik biasanya guru diberikan motivasi. Setiap anak pasti memberikannya berupa kata pujian, memiliki motivasi intrinsik karena mereka meminta siswa untuk menyaksikan video memiliki cita-cita yang diinginkan. Dan tentang motivasi ataupun memberikan juga mereka lebih terpacu jika ada kata-kata mutiara.

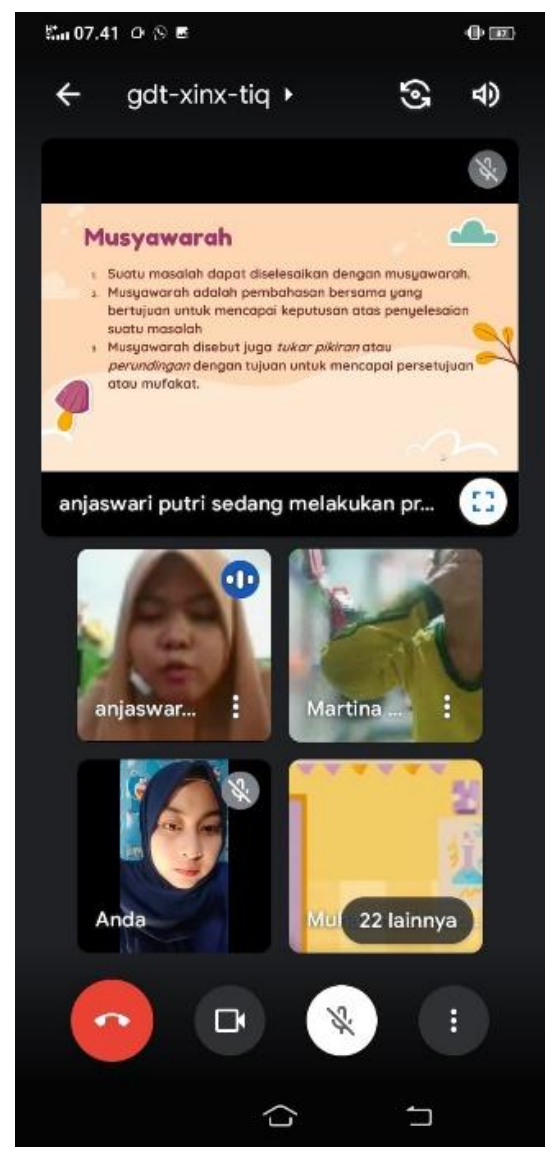

\section{Gambar 2: Pemberian Motivasi Guru dalam Pembelajaran Daring}

Dan juga peran orang tua sangat motivasi kepada anak agar dapat berpengaruh besar dalam memberikan mendapatkan hasil yang diinginkan. 
3. Upaya guru dalam menjaga kualitas motivasi belajar siswa terhadap pembelajaran keterampilan menyimak

Guru memiliki upaya untuk tetap menjaga kualitas motivasi belajar tersebut dengan cara memberikan motivasi seperti video atau memberikan kata kata semangat sebelum memulai pembelajaran, kata yang diberikan oleh guru seperti 'bagus nak, kamu hebat dan pintar anak sholeh dan sholehah".

Dan ditunjang dengan hasil wawancara antara peneliti dan guru. Berikut ini adalah hasil dari wawancara

\section{https://youtu.be/bPdHV9SPOsE}

Motivasi yang diberikan tentunya akan berdampak pada semangat belajar siswa terhadap keterampilan menyimak. Ketika proses pembelajaran jarak jauh berlangsung tidak dapat dipungkuri bahwa ada siswa yang tidak fokus karena ter-distract dengan yang ada dirumah, seperti adik, teman atau keluarga yang lain. Guru memiliki upaya agar siswa selalu fokus dan berpusat pada pembelajaran ketika guru sedang menerangkan. Guru biasanya memberikan aba-aba,karena aba-aba itu biasanya tidak hanya membuat anakanak senyap, bisa juga membuat memusatkan perhatian agar pusat perhatiannya terkumpul. Dan saya panggil satu-satu namanya untuk mencontohkan seperti yang ada di materi tentang pertemanan maka saya contohkan si A dan si B, nanti saya lihat satu-satu dari layar kaca.

\section{Kesimpulan}

Berdasarkan hasil penelitian dan pembahasan di atas dapat ditarik kesimpulan sebagai berikut yaitu Proses pembelajaran dalam analisis motivasi belajar pada keterampilan menyimak menggunakan google meet, whatsapp group dan website kejar cita. Dengan menggunakan media seperti power point, video dan gambar yang di sharescreen melalui aplikasi google meet. Faktor yang dapat meningkatkan motivasi belajar 
pada keterampilan menyimak Jenis upaya untuk tetap menjaga kualitas motivasi dibedakan menjadi dua yaitu motivasi belajar tersebut dengan cara motivasi ekstrinsik dan motivasi intrinsik, memberikan motivasi seperti video atau keduanya sangat berpengaruh dalam memberikan kata kata semangat sebelum sebuah proses pembelajaran. Upaya memulai pembelajaran. Motivasi yang guru dalam menjaga kualitas motivasi diberikan tentunya akan berdampak pada belajar siswa terhadap pembelajaran semangat belajar siswa terhadap keterampilan menyimak Guru memiliki keterampilan menyimak.

\section{Daftar Pustaka}

Anas. (2019). Pengaruh Motivasi Belajar dan Aktivitas Belajar terhadap Hasil Belajar Mahasiswa Program Studi PGSD. Cokroaminoto Journal.

Arianti. (2018). Peranan Guru dalam Meningkatkan Motivasi Belajar Siswa.

Diana. (2018). Penerapan Model Pembelajaran Attention, Relevance, Confindance, Dan Satification (ARCS) Dalam Meninangkatkan Motivasi Belajar IPA Kelas V MIN 10 Bandar Lampung. Bandar Lampung: UIN Raden Intan Lampung.

Dkk, F. (2018). Pengaruh Pendekatan Integratif Terhadap Keterampilan Menyimak Siswa Kelas V Sekolah Dasar Negeri Gerendeng 1 Kota Tangerang. Tangerang: Jurnal Pendidikan Dasar.

Dkk, F. (2020). Pengembangan Lks Tematik Bahasa Indonesia Kelas V Melalui Kegiatan Lesson Study Di Sekolah Dasar. Jurnal Cakrawala Pendas.

Dkk, H. (2018). Kemampuan Siswa Kelas V SD Negeri Gue Gajah Aceh Besar Menyimak Cerita Pendek. Jurnal IImiah Mahasiswa PGSD.

Dkk, H. (2020). Pengaruh Disiplin Belajar terhadap Hasil Belajar Bahasa Indonesia di Sekolah Dasar. Jurnal Basicedu.

Dkk, L. (2020). Cara Praktis Meningkatkan Motivasi Siswa Sekolah Dasar.

Dkk, R. (n.d.). Menyimak Berbicara Teori dan Teori .

Dkk, S. (2020). Pengaruh Profesionalisme Guru Terhadap Motivasi Belajar Siswa SD Negeri Sittah. Jorunal Of Primary Education.

Dkk, W. (2020). Analisis Motivasi Belajar Siswa dalam Pembelajaran IImu Pengetahuan Sosial di Kelas IV SDN Buluh 3 Socah.

86 | Autentik: Jurnal Pengembangan Pendidikan Dasar, Vol. 6, No. 1, Februari 2022 
Ernata. (2017). Analisis motivasi belajar peserta didik melalui pemberian reward dan punishment di sdn ngaringan 05 kec. gandusari kab. blitar. Blitar: JP2SD.

Farhrohman. (2017). Implementasi Pembelajaran Bahasa Indonesia di SD/MI.

Hakim, T. (2019). Belajar Secara Efektif.

Handayani, S. \&. (2021). Pengaruh Bimbingan Belajar terhadap Hasil Belajar Bahasa Indonesia Siswa Kelas Tinggi di Sekolah Dasar.

Iswatiningsih, S. \&. (2020). Belajar dan Pembelajaran di Era Milenial . Malang: Universitas Muhammadiyah Malang.

Izzah. (2018). Tingkat Keterampilan Menyimak Siswa Kelas V SDI Al-Barokah Kalijaga Tengah Tahun Pelajaran 2018/2019. Universitas Hamzanwawadi.

Kemdikbud. (2020). Kemendikbud Imbau Pendidik Hadirkan Belajar Menyenangkan Bagi Daerah yang Terapkan Belajar di Rumah. Jakarta: Kemdikbud.go.id.

Khair. (2018).

Khair. (2018). Pembelajaran Bahasa Indonesia dan Sastra (BASASTRA) di SD dan MI Ar Riayah. Jurnal Pendidikan Dasar.

Makarim, N. A. (2020). SURAT EDARAN MENTERI PENDIDIKAN DAN KEBUDAYAAN REPUBLIK INDONESIA. Jakarta: Kemdikbud.

Malang, H. \&. (2018). Hubungan Motivasi Belajar dan Tindakan Guru dengan Prestasi Belajar Siswa dengan Latar Belakang Broken Home Kelas V Sekolah Dasar.

Munajah, R. (2017). Manajemen Kelas Untuk Sekolah Dasar. Jakarta: Universitas Trilogi.

N, A. A. (2020). Pengaruh Motivasi Belajar Terhadap Prestasi Siswa di Sekolah. Jurnal Bimbingan Konseling.

Rahmawati. (2020). Pengaruh Model Pembelajaran Kontekstual Berbasis Kearifan Lokal Terhadap Keterampilan Menyimak Siswa.

Rambe. (2018). Penerapan Strategi Index Card Match Untuk Meningkatkan Hasil Belajar Siswa Pada Mata Pelajaran Bahasa Indonesia. Jurnal Tarbiyah.

Rani. (2019). Analisis Motivasi Belajar Siswa Pada Pembelajaran Bahasa Indonesia Di Kelas IV Sdn 1 Mlinjon Kecamatan Suruh Kabupaten Trenggalek Tahun Pelajaran 2018/2019. Trenggalek: Pena SD.

Saddhono. (2019). Menyimak Puisi.

Salsabila. (2020). Analisis Motivasi Belajar IPA Peserta Didik pada Pembelajaran ELearning Class di SMPIT Nidaul Hikmah Salatiga Selama Pandemi Covid-19.

87 | Analisis Motivasi Belajar pada Keterampilan Menyimak. 
Sriyanto, F. \&. (2021). ) Analisis keterampilan menyimak tayangan belajar di TVRI pada peserta didik kelas $V$ sekolah dasar.

Yulida, C. (2020). Analisis Keterampilan Mengajar Aspek Mengadakan Variasi dalam Pembelajaran Tematik Kelas IV di SDS Yasporbi I Pancoran Jakarta.

Yusandra, M. \&. (2017). Pengembangan RPKPS dan SAP Menyimak Berbasis Pendekatan Contekstual Teaching and Learning (CTL). . Jurnal Penelitian Bahasa dan Sastra Indonesia.

Riska. (2020). Pengaruh Keterampilan Menyimak Terhadap Hasil Belajar Peserta Didik di Kelas V SDN1 Balangnipa.

Yana, P. D. (2018). Pengaruh Menjelaskan Guru Terhadap Motivasi Belajar Siswa pada Mata Pelajaran Matematika di SDN 2 Margototo .

Kemdikbud. (n.d.). Data Sekolah. https://sekolah.data.kemdikbud.go.id/index.php/chome/profil/403FA995-2BF5E011-9581-97F6D5F87971.

SD Muhammadiyah 06 Tebet (n.d.). Profil Sekolah. https://sdmuh06tebet.sch.id/profilsd-muhammadiyah-06-tebet-timur. 